\title{
From funding liquidity to market liquidity: Evidence from the index options market
}

\author{
\begin{tabular}{l|l|l} 
Chunbo Liu $^{1}$ & Cheng Zhang (iD & Zhiping Zhou \\
\end{tabular}
}

${ }^{1}$ Institute of Financial Studies, Southwestern University of Finance and Economics, Chengdu, Sichuan, China

${ }^{2}$ School of Economics and Finance, Victoria University of Wellington, Wellington, New Zealand

${ }^{3}$ Department of Finance, School of Economics and Management, Wuhan University, Wuhan, Hubei, China

\section{Correspondence}

Zhiping Zhou, Department of Finance, School of Economics and Management, Wuhan University, Wuhan 430072, Hubei, China.

Email: zhiping.zhou@ whu.edu.cn
This study examines the relationship between funding liquidity and market liquidity using daily data on the S\&P 500 index options. We find that options market liquidity is positively correlated with funding liquidity after controlling for market uncertainty. Further analysis reveals that the positive relationship between funding liquidity and market liquidity in the options market is mainly driven by short-term and deep out-ofthe-money options. Our results remain robust after controlling for the confounding effects of the equity market and different data frequencies.

\section{K E Y W O R D S}

funding liquidity, options market liquidity, VIX

\section{1 | INTRODUCTION}

During the 2008 financial crisis, especially over the period when Lehman Brothers and other important financial institutions failed, funding for banks and non-financial firms was in short supply. A number of institutions failed due to difficulties in raising funds in illiquid markets. Motivated by this historical context, we examine the dynamic changes in market liquidity as they relate to changes in funding liquidity. This paper provides empirical evidence that options market liquidity is strongly influenced by funding liquidity, especially during periods of high market uncertainty. More specifically, we find that liquidity in the S\&P 500 index options market is positively correlated with funding liquidity after controlling for VIX, a broad-based measure of market uncertainty. ${ }^{1}$ This effect is more prominent when VIX is high.

A number of theoretical studies examine the link between market declines and asset illiquidity. Based on the idea that market liquidity depends on financial intermediaries' capital availability, Gromb and Vayanos (2002) show that when arbitrageurs have enough wealth, they fully absorb other investors' supply shocks, thus providing market liquidity; when arbitrageurs' capital is limited, however, market liquidity drops. In other words, arbitrageurs act as intermediaries by providing liquidity to other investors. Brunnermeier and Pedersen (2009) elaborate on the relationship between funding liquidity and market liquidity (FL-ML) and show that the two notions are mutually reinforcing, leading to liquidity spirals. They argue that a substantial market-wide decline in prices reduces the ease with which market makers can obtain funding, which, in turn, leads to higher comovement. Garleanu and Pedersen (2007) argue that tighter risk management reduces liquidity, which further tightens risk management. This feedback effect helps explain the connection between sudden drops in liquidity and increased volatility. In his 2010 AFA presidential address, Duffie (2010) argues that the financial crisis and the resulting slow movement of investment capital increased the cost of intermediation and thus led to increases in trading spreads. Moreover, Duffie (2012) points out that

\footnotetext{
${ }^{1}$ VIX is calculated by the Chicago Board Options Exchange (CBOE), which measures the implied volatility of options on the S\&P 500 index. It is often referred to as the fear index or the fear gauge.
} 
the 2008 financial crisis not only affected banks' lending function, but also had a major impact on market liquidity. He further argues that investors and issuers of securities found it more costly to raise capital and obtain liquidity for their existing positions during the recent financial crisis.

The implications of these important theoretical findings have not been fully investigated from an empirical point of view; to the best of our knowledge, there has not been a thorough empirical analysis of the relationship between market liquidity and funding liquidity over an extended period of time. The relationship between funding liquidity and market liquidity in the stock market has been tested by Hameed, Kang, and Viswanathan (2010) with pre-crisis data. After the 2008 crisis, researchers have investigated the relationship between funding liquidity and the market liquidity of the stock market (see e.g., Hu, Jain, \& Jain, 2013), the corporate bond market (see e.g., Dick-Nielsen, Gyntelberg, \& Lund, 2013), and the foreign exchange market (see e.g., Coffey, Hrung, \& Sarkar, 2009; Mancini, Ranaldo, \& Wrampelmeyer, 2013). However, no previous studies have examined the dynamics of funding liquidity and options market liquidity.

This paper presents one of the first systematic empirical studies of liquidity in the S\&P 500 index options market and analyzes the impact of funding liquidity on index options market liquidity using a sample that covers the recent financial crisis. We measure liquidity in the index options market on a daily basis, relate index options market liquidity to measures of funding liquidity as well as the liquidity of equity markets, and provide solid evidence to support the theoretical predictions of Brunnermeier and Pedersen (2009), and Gromb and Vayanos (2002). This paper tests and validates the following hypotheses: options market liquidity is positively correlated with funding liquidity and this effect is more prominent during periods of high market uncertainty (H1); and call and put options' market liquidity responds differently to funding liquidity (H2).

We compute options liquidity using a comprehensive database. Our sample period ranges from January 2003 to January 2012, including the entire financial crisis. Following Chordia, Roll, and Subrahmanyam (2000), and Cao and Wei (2010), we use the proportional bid-ask (PBA) spread as our measure of index options liquidity. We compute the PBA spread by dividing the difference between ask and bid quotes by the midquote. We use the TED spread, the difference between the 3-month LIBOR and the 3-month U.S. Treasury bill rate, as a proxy for the level of funding liquidity. ${ }^{2}$

We retrieve the residual of the TED spread from an OLS regression of the TED spread on VIX in order to isolate the effect of funding liquidity from the influence of market-wide uncertainty. The residual from the aforementioned regression, Residual $_{T E D \mid V I X}$, is then included in an ARMAX model as an exogenous regressor along with VIX to examine the relation between liquidity in the index options market and funding costs. The relationship between the PBA spread and the Residual $_{T E D \mid V I X}$ is positive throughout the whole sample period, and the coefficient is statistically significant at the $1 \%$ level. ${ }^{3}$ In particular, a one-standard-deviation increase in the Residual $_{T E D \mid V I X}$ translates into an increase in the bid-ask spread of 0.49 basis point, which is about $11 \%$ of its standard deviation. The findings lend support to our first hypothesis (that market liquidity declines when liquidity providers face high funding costs).

We then examine whether the effect of funding liquidity on options market liquidity depends on market uncertainty. We test this conjecture by interacting the TED spread with VIX. We find that shocks to funding liquidity positively affect options market liquidity only when VIX is sufficiently high, which implies that our main findings are very likely "conditional.', This "conditional" effect can be observed for both call and put options and for options with different characteristics. ${ }^{4}$ For instance, we only observe call options liquidity deteriorating significantly following an increase in funding costs when VIX is higher than $28 \%$. For put options, the corresponding threshold value of VIX is $14 \%$. Considering that the sample median of VIX is $18 \%$, our findings indicate that put options market liquidity reacts to funding liquidity shocks in a less "conditional" manner. Since market uncertainty (VIX) stays at relatively high levels for years after the crisis, the "conditional" effect we document cannot be attributed to the financial crisis.

Cao and Wei (2010) show that the effect of market movements on options liquidity differs between calls and puts. Specifically, the liquidity of calls mostly responds to upward market movements, while the liquidity of puts responds mostly to downward movements. One can therefore expect that the liquidity of put options mostly responds to funding liquidity during periods

\footnotetext{
${ }^{2}$ It is common to employ the TED spread as a proxy for funding liquidity (see e.g., Boyson, Stahel, \& Stulz, 2010; Brunnermeier, Nagel, \& Pedersen, 2008; Brunnermeier \& Pedersen, 2009; Hameed et al., 2010). We also run our analyses using an alternative proxy for funding liquidity: the LIBOR-OIS spread, calculated as the difference between the LIBOR and the overnight index swap rate (OIS). The results based on the LIBOR-OIS spread are similar and are available upon request.

${ }^{3}$ An ARMAX is estimated to fit the time series of the PBA spread, which is serially correlated and can be explained by exogenous variables, such as VIX and the Residual TEDIVIX . AIC and BIC are employed to determine the optimal number of lags of autoregressive and moving average terms.

${ }^{4}$ We are very cautious in generalizing this conclusion to a broader set of assets because of the distinctive features of options, as well as their distinctive relation with market uncertainty compared with other types of financial instruments.
} 
of high market uncertainty. Our results show that the liquidity of calls and puts indeed responds asymmetrically to funding liquidity.

We further split the sample according to maturity and moneyness (the ratio between the strike price and the underlying spot price) of each option to study how the effect of funding liquidity on options market liquidity is distributed across options of various maturities and moneyness levels. We maintain the same specification of the ARMAX model, linking the options market liquidity to funding liquidity and VIX. This exercise is related to the growing literature on the information content of option trading (see e.g., Cao, Chen, \& Griffin, 2003; Easley, O'hara, \& Srinivas, 1998; Jayaraman, Frye, \& Sabherwal, 2001; Vijh, 1990). Trading deep out-of-the money options takes advantage of high leverage, even though these options are generally less liquid and have high proportional bid-ask spreads. In the presence of superior information, however, the leverage effect may dominate the liquidity consideration. Similarly, to avoid a high option premium, one may prefer a short-term option over a longterm one, as the former offers high leverage. One can therefore expect that the relationship between funding liquidity and options market liquidity is mainly driven by short-term and deep out-of-the-money options. First, we document a positive relationship

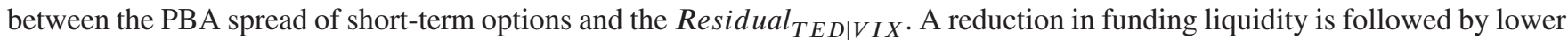

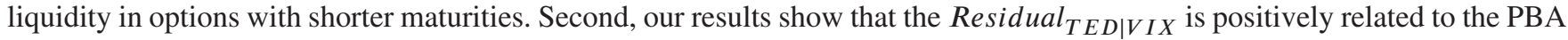
spread and significant in explaining the liquidity of options with different levels of moneyness.

Finally, we conduct two robustness tests. First, we try to rule out the possibility that the observed FL-ML relationship in the options market results from an association between funding liquidity and liquidity in the equity market. We show that our main results remain robust after controlling for several measures of stock market liquidity. Second, we reexamine the main findings using weekly data. In general, the results are similar to those calculated using daily data.

Our paper is related to the growing literature investigating the relationship between funding liquidity and market liquidity. Chordia et al. (2005) examine liquidity movements in stock and Treasury bond markets using daily data and build a link between macro liquidity, or money flows, and micro liquidity, or transactions. Using a dummy variable as a proxy for the period of low funding liquidity, Hameed et al. (2010) test the relationship between funding liquidity and market liquidity in the stock market but only cover pre-crisis data. Hu et al. (2013) explore the non-linear FL-ML relationship in the stock market and show that this relationship weakens after the enactment of the Volcker Rule. Dick-Nielsen et al. (2013) investigate how funding liquidity affects bond market liquidity in Denmark. They find that the ease of obtaining term funding in the money markets determines the liquidity in the bond market for both long- and short-term bonds. Mancini et al. (2013) use intraday trading and order data to measure liquidity in the foreign exchange (FX) market and show that negative shocks in funding liquidity lead to significantly lower FX market liquidity and systematic FX liquidity comoves with equity liquidity.

Our paper is also related to the literature focusing on liquidity in the options market. While an extensive literature investigating liquidity in the equity market exists, liquidity in the options market is much less studied, despite the fact that the options market is by far one of the most important financial markets in the United States. ${ }^{5}$ Jameson and Wilhelm (1992) show that options' bid-ask spreads are determined by market makers' ability to rebalance options positions as well as uncertainty regarding the return volatility of the underlying stocks. Employing a simultaneous equation system, George and Longstaff (1993) examine how call and put options' bid-ask spreads affect their trading activity. They find that the bid-ask spread negatively affects trading volume, and that calls and puts are substitutes in terms of trading activity. A recent paper by Wei and Zheng (2010) studies the relation between trading activity and bid-ask spread on the individual option level. Using data on market makers' inventory positions, $\mathrm{Wu}, \mathrm{Liu}, \mathrm{Lee}$, and Fok (2014) consider the price risk for market makers and show that it is not significantly related to option spreads. Using Ivy DB's OptionMetrics data, Cao and Wei (2010) examine the commonality among various liquidity measures such as the bid-ask spread, trading volumes and price impact. In addition, they establish that options liquidity responds asymmetrically to upward and downward market movements. Furthermore, several studies investigate the effect of liquidity on derivative prices. In an extended Black-Scholes economy, Cetin, Jarrow, Protter, and Warachka (2006) derive the prices of options with illiquid underlying assets. Their empirical results support the conjecture that liquidity costs account for a significant portion of the option price. Bongaerts, de Jong, and Driessen (2011) develop a theoretical asset pricing model of liquidity effects in derivative markets and test the pricing of liquidity for the credit default swap market. Using the OTC euro interest rate cap and floor data, Deuskar, Gupta, and Subrahmanyam (2011) find that illiquid options trade at higher prices relative to liquid options.

The rest of this paper is organized as follows. In section 2, we describe the data, define the liquidity measures, and report the summary statistics. Section 3 presents the main results concerning the dynamics of market liquidity and funding liquidity. Robustness tests are provided in section 4 . Section 5 concludes.

\footnotetext{
${ }^{5}$ In the United States, the trading volume of individual stock options has grown exponentially from 5 million contracts in 1974 to more than 3,727 million contracts in 2015 (http://www.optionsclearing.com/webapps/historical-volume-query).
} 


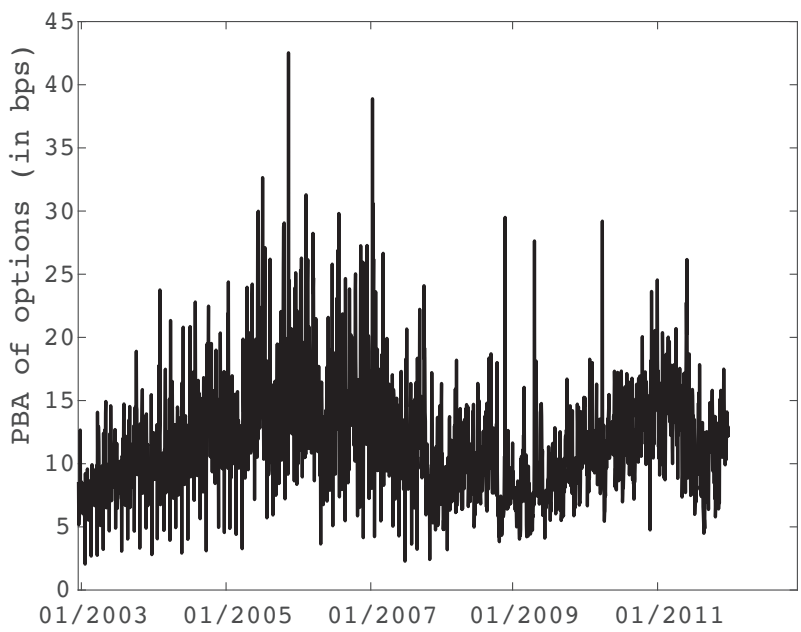

FIGURE 1 The evolution of options market liquidity. This figure illustrates the evolution of the index options market liquidity from January 2003 to January 2012. The (volume-weighted) proportional bid-ask spread is used as a proxy for options market liquidity; its definition can be found in the Appendix

\section{2 | DATA AND VARIABLES}

In this section, we first discuss the data used to construct liquidity measures. We then describe how these measures are calculated and report their summary statistics.

\section{1 | Data}

Our data consist of daily closing bid and ask quotes, daily volume, and open interest on the S\&P 500 index options. We cover the period from January 17, 2003, to January 31, 2012, for a total of 2,263 trading days, including the height of the recent financial crisis in the fall of 2008. We extract the options data from the OptionMetrics IVY DB, which includes daily best bid and ask closing quotes, open interest, and volume for each option. We then apply several filters to minimize possible data errors. To eliminate outliers and options with non-standard features, we discard options with missing implied volatilities. Further, we drop observations violating basic no-arbitrage conditions. We also remove all options with zero bid prices.

In addition to the whole sample analysis, we split the sample according to several characteristics to obtain a clearer picture. Following Bakshi, Cao, and Chen (1997), we first split options into three categories by time-to-maturity, measured in calendar days to expiration ( $A D T E_{i, t}$ ): short-term (less than 60 days), medium-term (between 60 and 180 days), and long-term (more than 180 days). Second, we categorize options by their moneyness ( $m_{i, t}$, the ratio between strike price and the underlying spot price), dividing them into five groups as follows: deep out-of-the-money (DOTM) if $m_{i, t}>1.06$ for calls or $m_{i, t}<0.94$ for puts, out-ofthe-money (OTM) if $1.01<m_{i, t} \leq 1.06$ for calls or $0.94 \leq m_{i, t}<0.99$ for puts, at-the-money (ATM) if $0.99 \leq m_{i, t} \leq 1.01$ for both puts and calls, in-the-money (ITM) if $0.94 \leq m_{i, t}<0.99$ for calls or $1.01<m_{i, t} \leq 1.06$ for puts, and deep in-the-money (DITM) if $m_{i, t}<0.94$ for calls or $m_{i, t}>1.06$ for puts (Goncalves \& Guidolin, 2006).

Following Cao and Wei (2010), we compute the proportional bid-ask spread (PBA) of each individual option by dividing the difference between the ask and bid quotes by the mid-quote. We then calculate a volume-weighted average of each option's proportional spreads and use this daily average to implement our analysis. ${ }^{6}$

The funding liquidity measure used in this paper is the TED spread, which is provided by the Federal Reserve Bank in St. Louis. Our proxy for market-wide uncertainty is the Chicago Board Options Exchange Volatility Index (VIX), which is frequently used as a proxy for investors' fear and uncertainty in financial markets. Figures 1-3 depict the evolution of options liquidity (PBA), the TED spread, and VIX from January 2003 to January 2012. Both the TED spread and VIX exhibited sharp spikes during the financial crisis, while the options market bid-ask spread reached its lowest level during this period. The options market's "cooling down" during the boom and "heating up" during the crisis point directly to its distinctive features.

${ }^{6}$ The option liquidity measures are defined in the Appendix. In an unreported analysis, we weigh the bid-ask spread by the corresponding open interest and find that all results remain qualitatively similar. 


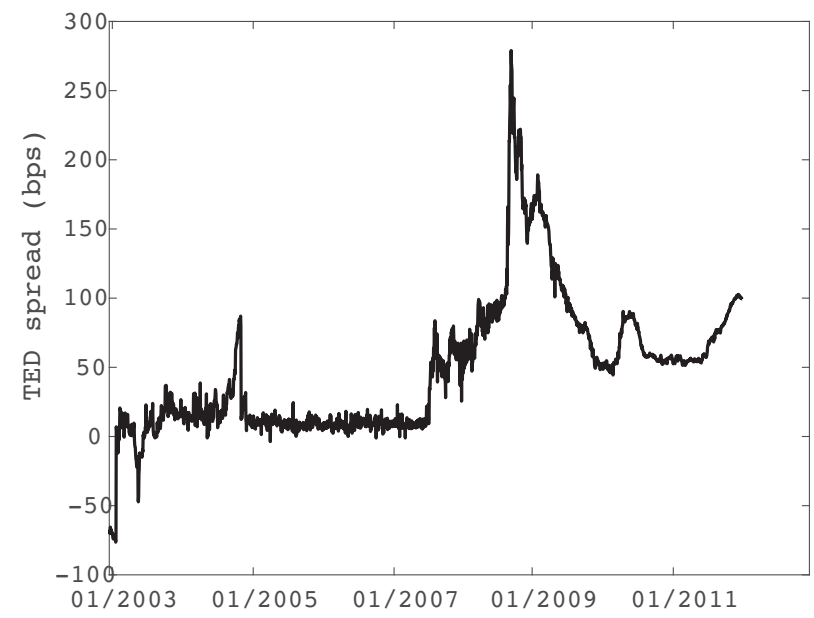

FIGURE 2 The evolution of the TED spread. This figure illustrates the evolution of the TED spread (bps) from January 2003 to January 2012

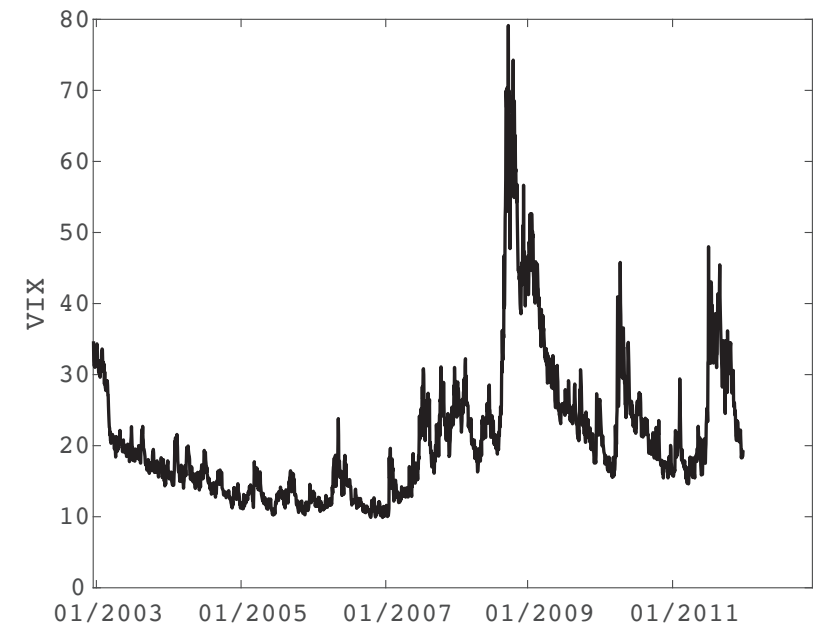

FIGURE 3 The evolution of VIX. This figure illustrates the evolution of VIX (\%) from January 2003 to January 2012

\subsection{Summary statistics}

Table 1 presents the summary statistics of both the bid-ask spreads of various types of options and the key explanatory variables. In addition to presenting data for the whole sample, we also divide the sample period into three sub-periods: the pre-crisis period (01/2003-07/2007), the crisis period (08/2007-06/2009), and the post-crisis period (07/2009-01/2012). During the whole sample period, the mean bid-ask spread for all options is 12 basis points. This is consistent with the calculation in Cao and Wei (2010), who find 13 basis points bid-ask spread during the period from 1996 to 2004. Since our sample period spans the financial crisis when the options market was relatively more liquid, it is unsurprising that the PBA spread is somewhat lower in this study. Several other details are also worth noting. First, compared with call options, put options have a smaller bid-ask spread in terms of both the mean and the median. The higher liquidity for puts in our paper might be attributed to the high transaction activity during the financial crisis. Second, options in general become more liquid during the financial crisis. For instance, options are traded with an average bid--ask spread of 13 basis points before the crisis and 12 basis points afterward. During the crisis, the bid-ask spread narrows to 10 basis points. This pattern applies to different types of options, regardless of maturity or moneyness. ${ }^{7}$

Panel B contains the means, medians, and standard deviations for the independent regressors used in this paper. Both the TED spread and the VIX increase dramatically as the financial crisis unfolds. The TED spread is more than ten times higher after the crisis, indicating that funding liquidity drops suddenly in this period. Similarly, VIX is almost twice as high as during

\footnotetext{
${ }^{7}$ An exception is deep in-the-money options, which trade with higher bid-ask spreads during the crisis than before it.
} 
TABLE 1 Summary statistics

\begin{tabular}{|c|c|c|c|c|c|c|c|c|c|c|c|c|}
\hline \multirow{2}{*}{$\begin{array}{l}\text { Sample period } \\
\text { Statistics }\end{array}$} & \multicolumn{3}{|c|}{ Whole sample } & \multicolumn{3}{|c|}{ Before crisis } & \multicolumn{3}{|c|}{ During crisis } & \multicolumn{3}{|c|}{ After crisis } \\
\hline & Mean & Med. & Std. & Mean & Med. & Std. & Mean & Med. & Std. & Mean & Med. & Std. \\
\hline All options & 11.84 & 11.4 & 4.34 & 12.82 & 12.37 & 4.75 & 9.69 & 9.18 & 3.52 & 11.68 & 11.54 & 3.46 \\
\hline Call options & 12.67 & 11.99 & 5.21 & 13.14 & 12.25 & 5.89 & 10.81 & 10.25 & 4.17 & 13.19 & 12.92 & 4.26 \\
\hline Short-maturity & 13.64 & 13.09 & 5.10 & 14.62 & 14.06 & 5.49 & 11.36 & 10.79 & 4.21 & 13.59 & 13.12 & 4.38 \\
\hline Medium-maturity & 7.82 & 7.61 & 2.87 & 8.52 & 8.25 & 2.94 & 6.29 & 5.79 & 2.51 & 7.70 & 7.50 & 2.54 \\
\hline Long-maturity & 4.96 & 4.76 & 1.81 & 5.31 & 5.08 & 1.93 & 3.95 & 3.72 & 1.66 & 5.07 & 4.75 & 1.40 \\
\hline Out-of-the-money & 12.60 & 11.88 & 5.08 & 13.88 & 13.16 & 5.47 & 9.86 & 9.35 & 3.64 & 12.34 & 11.78 & 4.39 \\
\hline Deep in-the-money & 2.69 & 2.47 & 1.08 & 2.16 & 2.12 & 0.57 & 2.95 & 2.49 & 1.52 & 3.17 & 3.13 & 0.86 \\
\hline \multicolumn{13}{|l|}{ Panel B: Explanatory variables } \\
\hline TED spread (\%) & 0.48 & 0.41 & 0.50 & 0.10 & 0.10 & 0.18 & 1.09 & 0.91 & 0.56 & 0.70 & 0.61 & 0.17 \\
\hline VIX (\%) & 21.09 & 18.53 & 9.89 & 15.42 & 14.32 & 4.61 & 31.50 & 26.22 & 13.06 & 23.46 & 22.22 & 6.21 \\
\hline Stock bid-ask spread (ew) & 0.14 & 0.12 & 0.36 & 0.13 & 0.13 & 0.02 & 0.23 & 0.17 & 0.79 & 0.09 & 0.08 & 0.03 \\
\hline Stock bid-ask spread (vw) & 0.02 & 0.02 & 0.02 & 0.02 & 0.02 & 0.01 & 0.04 & 0.03 & 0.02 & 0.01 & 0.01 & 0.00 \\
\hline Stock trading volume (billion \$) & 6.30 & 5.71 & 2.64 & 4.29 & 4.18 & 0.96 & 8.66 & 8.33 & 2.54 & 8.10 & 7.82 & 1.89 \\
\hline
\end{tabular}

This table shows summary statistics for options liquidity and other variables used in this study. The sample period is divided into three sub-periods: the pre-crisis period (01/2003-07/2007), the crisis period (08/2007-06/2009), and the post-crisis period (07/2009-01/2012). As shown in Panel A, the proportional bid-ask spread is used as the measure of options liquidity and is expressed in basis points. Aside from presenting separate liquidity measures for calls and puts, this table also reports liquidity measures for subgroups of options with varying maturity and moneyness. Panel B presents summary statistics of the independent variables used in this paper. Here ew stands for equally weighted, while $v w$ stands for value weighted.

the crisis than before it, implying that the market uncertainty, as perceived by investors, increases after the inception of the crisis. We also examine the dynamics of stock market liquidity, measuring both bid-ask spreads and volume. The U.S. stock market has an average bid-ask spread of 14 cents when equally weighted and 2 cents when value weighted. The mean daily volume and dollar volume are 6.3 billion and 189 billion dollars, respectively. In contrast to the options market, the stock market becomes much less liquid during the financial crisis.

\section{3 | EMPIRICAL RESULTS}

To model the relationship between options market liquidity and funding liquidity or market uncertainty, we first have to test for the stationarity of these time series. The Augmented Dickey Fuller (ADF) test result, shown in Table 2, reveals that all of the variables of interest are stationary. The null hypothesis of unit root is rejected at $1 \%$ for all of our series. Therefore, we choose ARMAX to model the effect of funding liquidity and market uncertainty on options market liquidity. ${ }^{8}$ Given the high correlation between the TED spread and VIX ( 0.776 over the entire sample period), we isolate the effect of funding liquidity from the influence of market uncertainty. We adopt a two-step procedure in which only that part of the TED spread which is

\footnotetext{
${ }^{8}$ For each specification in this paper, we also run OLS regressions with Newey and West (1987) standard errors. The number of lags used to calculate Newey-West standard errors is set to 7 , the closest integer to the fourth root of the number of observations in our main sample, as suggested by Greene (2011). All results are qualitatively similar to those generated by ARMAX. Results from Newey-West regressions are available upon request.
} 
TABLE 2 Stationarity test for key variables

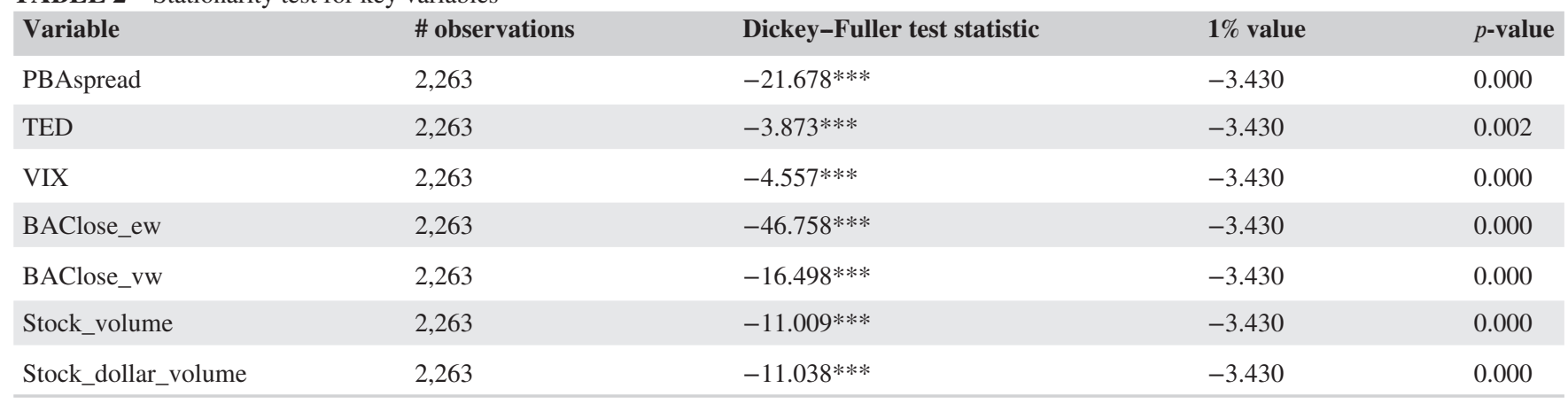

This table show the results of the stationarity test for key variables used in this paper, namely proportional bid-ask spread (PBAspread), volume, dollar volume, the TED spread, VIX and several stock market liquidity measures. Augmented Dickey-Fuller test statistics and the $1 \%$ critical value are reported, with the corresponding $p$-value shown in the last column. Here $e w$ stands for equally weighted. $* * *, * *$, and $*$ denote significance at the $1 \%, 5 \%$, and $10 \%$ levels, respectively.

orthogonal to VIX is used to predict options market liquidity. Specifically, we first run an OLS regression in which the TED spread is regressed on VIX:

$$
T E D_{t}=\alpha_{0}+\alpha_{1} V I X_{t}+\mu_{t}
$$

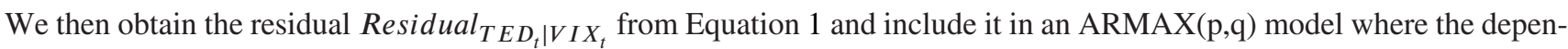
dent variable is the PBA spread of the index options market:

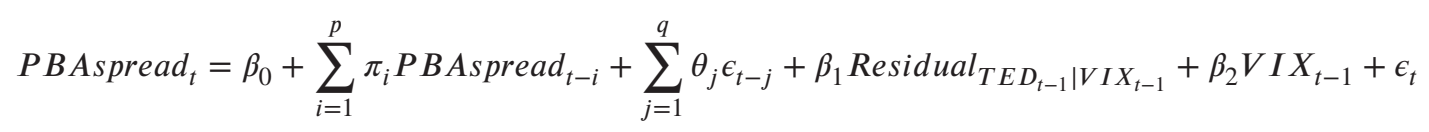

where $p$ and $q$ are the numbers of lags for autoregressive and moving average terms, respectively. $\beta_{1}$ and $\beta_{2}$ are the coefficients of the residual of the TED spread and VIX, respectively. We use the Akaike information criterion (AIC) and the Bayesian information criterion (BIC) to determine the optimal number of lags.

\section{1 | Main results}

Table 3 shows the results of the ARMAX regressions linking liquidity in the options market to funding costs and VIX over the entire sample period from January 17, 2003, to January 31, 2012. After controlling for the lagged proportional bid-ask (PBA) spread, we first regress the PBA spread on Residual $_{T E D_{t} \mid V I X_{t}}$ and VIX using simple OLS. In line with Hypothesis 1, we find a significantly positive relationship between the current PBA spread and the previous day's Residual $T E D \mid V I X$. The coefficient is statistically significant at the $1 \%$ level. A one-standard-deviation increase in $\operatorname{Residual}_{T E D \mid V I X}(0.32 \%)$ is associated with a 0.26 basis point increase in the PBA spread, which is about $6 \%$ of its standard deviation. As shown in column (1), the relationship between the PBA spread and VIX is significantly negative. In terms of magnitude, when market uncertainty increases by one standard deviation (9.89\%), the options market bid-ask spreads on the following day decline by 1.34 basis points, which is about $31 \%$ of their standard deviation. This effect is the opposite of the phenomenon Mancini et al. (2013) find in the currency market, where an increase in market uncertainty is followed by a decline in FX market liquidity. This difference arises from the fact that the convex payoff structure allows options to act as hedges for volatility, which is higher during periods of high market uncertainty. Note that we control for one lag in the proportional bid-ask spread; in OLS regressions that do not control for lags in the PBA spread, the magnitude of the effect doubles.

In column (2), we estimate an ARMAX model with four autoregressive and three moving average terms, which generates the baseline result of this paper. Residual ${ }_{T E D \mid V I X}$ and VIX with a one-day lag are included as regressors. The results are similar to those in the OLS estimation. However, the magnitude of the effect of Residual $_{T E D \mid V I X}$ on the bid-ask spread is about twice as high, highlighting the necessity of taking into account the autocorrelation within the PBA spread at higher orders. Here, a one-standard-deviation increase in $\operatorname{Residual}_{T E D \mid V I X}$ leads to an increase of 0.49 basis point in the bid-ask spread, which is about $11 \%$ of its standard deviation. Therefore, after controlling for VIX, options market liquidity declines when liquidity providers face higher funding costs, consistent with the theoretical predictions of Brunnermeier and Pedersen (2009) and Gromb and Vayanos (2002). 
TABLE 3 Funding liquidity and options market liquidity

\begin{tabular}{|c|c|c|c|c|c|c|c|}
\hline & (1) & (2) & (3) & (4) & (5) & (6) & (7) \\
\hline Sample & All & All & Call & Put & All & Call & Put \\
\hline Residual $_{T E D_{t-1} \mid V I X_{t-1}}$ & $(3.40)$ & (1.98) & $(0.61)$ & $(2.40)$ & & & \\
\hline$T E D_{t-1}$ & & & & & -1.350 & -1.856 & -1.283 \\
\hline \multirow[t]{2}{*}{$V I X_{t-1}$} & $-0.136^{* * *}$ & $-0.057 * *$ & $-0.074 *$ & $-0.051^{*}$ & $-0.218 * * *$ & $-0.179 * * *$ & $-0.249 * * *$ \\
\hline & $(-10.60)$ & $(-2.04)$ & $(-1.96)$ & $(-1.68)$ & $(-5.64)$ & $(-3.55)$ & $(-5.95)$ \\
\hline \multirow[t]{2}{*}{$T E D_{t-1} \times V I X_{t-1}$} & & & & & $0.077 * * *$ & $0.067 * *$ & $0.091 * * *$ \\
\hline & & & & & $(2.92)$ & $(2.05)$ & $(3.52)$ \\
\hline 1 & (21.97) & (33.52) & (16.86) & (13.78) & (74.70) & (13.75) & (12.70) \\
\hline \multirow[t]{2}{*}{2} & & $-2.226 * * *$ & $-0.525 * * *$ & $-1.572 * * *$ & $-4.508 * * *$ & $-1.395^{* * *}$ & $-1.510^{* * *}$ \\
\hline & & $(-15.50)$ & $(-5.84)$ & $(-6.26)$ & $(-37.96)$ & $(-11.08)$ & $(-5.63)$ \\
\hline \multirow[t]{2}{*}{3} & & $0.914 * * *$ & & $0.457 * * *$ & $2.857 * * *$ & $1.340 * * *$ & $0.430 * * *$ \\
\hline & & $(8.05)$ & & $(4.56)$ & $(24.09)$ & (11.39) & $(4.01)$ \\
\hline 4 & & $(-2.24)$ & & & $(-15.69)$ & $(-4.25)$ & \\
\hline Model & OLS & $\operatorname{ARMAX}(4,3)$ & $\operatorname{ARMAX}(2,2)$ & $\operatorname{ARMAX}(3,3)$ & $\operatorname{ARMAX}(4,4)$ & $\operatorname{ARMAX}(4,4)$ & $\operatorname{ARMAX}(3,3)$ \\
\hline$(N)$ & 2,263 & 2,263 & 2,263 & 2,263 & 2,263 & 2,263 & 2,263 \\
\hline
\end{tabular}

This table shows the results of ARMAX regressions linking liquidity in the options market to funding costs and market uncertainty. The proxy for market uncertainty is VIX, the CBOE S\&P 500 volatility index. Our measure of funding costs is the TED spread, defined as the difference between the 3-month LIBOR rate and the rate of U.S. Treasury bills with the same maturity. We adopt a two-step procedure in which only the part of TED spread that is orthogonal to VIX is used to predict options market liquidity. Specifically, we first run an OLS regression where the TED spread is regressed on VIX, with the specification as follows.

$$
T E D_{t}=\alpha_{0}+\alpha_{1} V I X_{t}+\mu_{t}
$$

The residual from the above regression, Residual TED $\mid V I X_{t}$, is then included in an ARMAX(p,q) model as an exogenous regressor along with VIX. Both VIX and the residual of the TED spread are lagged for one period (day). The optimal number of lags of the AR and MA terms is selected according to BIC and AIC information criteria. Columns (1)-(4) include lagged VIX and lagged Residual ${ }_{T E D \mid V I X}$ as exogenous regressors, while Columns (5)-(7) add the interaction term between VIX and the TED spread into the regression. Below the exogenous regressors are several autoregressive terms for each ARMAX model. For brevity, the coefficients of moving averaging terms are not displayed. $T$-statistics are shown below the coefficient estimates inside parentheses. $* * *, * *$, and $*$ denote significance at the $1 \%, 5 \%$, and $10 \%$ levels, respectively.

In columns (3) and (4), we investigate whether the effect of funding liquidity and market uncertainty on options liquidity differs between calls and puts. As in previous regressions, we find a significantly negative relationship between the PBA spread and VIX, in both the call and the put samples. This finding suggests that rising market-wide uncertainty contributes to a lower bid-ask spread for both call and put options. The magnitude of VIX's effect on the PBA spread is lower in the put options sample. For call options, a one-standard-deviation increase in VIX leads the PBA spread to decrease by $14 \%$ of its standard deviation. For puts, the sensitivity of options liquidity to uncertainty is lower. A one-standard-deviation shock to VIX at time $t-1$ leads to a change of $11 \%$ of a standard deviation at time $t$.

Interestingly, we only find a positive relationship between market liquidity and funding liquidity for put options. A onestandard-deviation increase in Residual ${ }_{T E D \mid V I X}$ is followed by a 0.65 basis point increase in the PBA spread, which is equivalent to $14 \%$ of its standard deviation. This effect is higher than that for the whole sample of options, and lends support to Hypothesis 2. Overall, these results support our hypothesis that market liquidity deteriorates when the supply of capital is tight. We also show that the options market becomes more liquid during periods of high market uncertainty.

We then examine whether the effect of funding liquidity on index options market liquidity is more prominent during periods of high uncertainty. We test this prediction by interacting the TED spread with VIX. If the effect is magnified when marketwide uncertainty is high, one can expect the interaction term to be significantly positive. As shown in columns (5)-(7), the 
interaction term is positive and statistically significant, irrespective of the sample we use. However, the TED spread alone becomes insignificant and negative, indicating that the effect of funding liquidity on index options market liquidity is very likely to be conditional in nature. In other words, the index options market becomes illiquid following a shock to funding liquidity only when market-wide uncertainty is high. For instance, as indicated in column (5), when VIX is below 17\%, index options's PBA spread reacts negatively to shocks to the TED spread. ${ }^{9}$ This relationship, however, becomes positive as VIX moves above $17 \%$. According to columns (6) and (7), the market liquidity for call and put options is positively correlated with funding liquidity only when VIX exceeds $28 \%$ and $14 \%$, respectively. Obviously, put options market liquidity reacts to funding liquidity shocks in a less "conditional" manner, showing that put options are more sensitive to shocks to funding liquidity. These results are consistent with the empirical findings of Cao and Wei (2010), who argue that the liquidity levels of puts and calls respond asymmetrically to market movements. Specifically, they document that put options' liquidity responds mostly to downward movements.

\section{2 | Subsample analysis}

To more deeply understand the response of options market liquidity to changes in funding liquidity, we further split the sample in three ways: (1) options with short, medium and long maturity; (2) options with different levels of moneyness; and (3) call and put options with different levels of moneyness.

\subsection{1 | Maturity}

In Table 4, we split the sample according to maturity (short-term if $A D T E_{i, t}<60$; medium-term if $60 \leq A D T E_{i, t} \leq 180$; longterm if $A D T E_{i, t}>180$ ). To avoid a high option premium, one may prefer a short-term option over a long-term one, as the former offers high leverage and is generally more liquid. One can therefore expect that the FL-ML relationship is mainly driven by short-term options. Table 4 shows the results of ARMAX regressions linking the liquidity of options with various maturities to funding costs and VIX over the entire sample period. While VIX has a strong negative relationship with short-, medium-, and long-term options, the magnitude of its effect on the bid-ask spread is greatest by far for short-term options. Thus, the liquidity of options with different maturities responds asymmetrically to market movements.

In column (1), we document a positive relationship between the PBA spread of short-term options and $\operatorname{Residual}_{T E D \mid V I X}$, which is significant at the $10 \%$ level. Thus, a reduction in funding liquidity is followed by a lower market liquidity level for shortterm options. In contrast, the coefficients on Residual $_{T E D \mid V I X}$ are not significant for options with longer maturities. This lends support to our conjecture that the relationship between funding liquidity and market liquidity is mainly driven by short-term options.

As in section 3.1, we include the interaction term between the TED spread and VIX to examine whether the effect of funding liquidity on options liquidity is more pronounced during periods of high market uncertainty. Columns (4)-(6) show that the market liquidity for short-, medium-, and long-term options increases with funding liquidity only when VIX is larger than $18.6 \%, 29.9 \%$, and $33.7 \%$, respectively. This further demonstrates that short-term options are more sensitive to changes in funding costs; thus, the FL-ML relationship is mainly driven by short-term options.

\subsection{2 | Moneyness}

Next, we split our sample according to options' moneyness levels. Options are divided into five categories, namely, deep outof-the-money (DOTM), out-of-the-money (OTM), at-the-money (ATM), in-the-money (ITM), and deep in-the-money (DITM). Trading deep out-of-the money options takes advantage of high leverage, though these options are generally less liquid and have high proportional bid-ask spreads. In the presence of superior information, however, the leverage effect may dominate the liquidity consideration. Consequently, we expect that the relationship between FL and ML is mainly driven by deep out-of-themoney options. Our results, shown in Table 5, indicate that both DOTM and DITM options liquidity responds significantly to

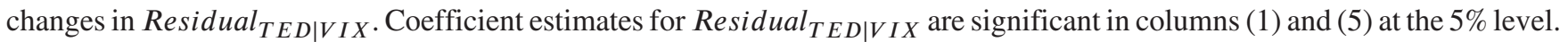

Moreover, we find that although market uncertainty continues to have a significant impact on options liquidity, the effect exhibits substantial heterogeneity among options with different levels of moneyness. Specifically, the coefficient estimates of VIX indicate that DOTM and OTM options become more liquid following an increase in market uncertainty, whereas DITM options exhibit the opposite behavior. Coefficient estimates in columns (1)-(2) and (6)-(7) indicate that DOTM and OTM

${ }^{9}$ When VIX is equal to $17.5 \%(1.35 / 0.077=17.53)$, the marginal effect of the TED spread on the PBA spread is close to zero. The effect thus becomes negative when VIX is below $17 \%$. 
TABLE 4 Funding liquidity and the liquidity of options with different maturities

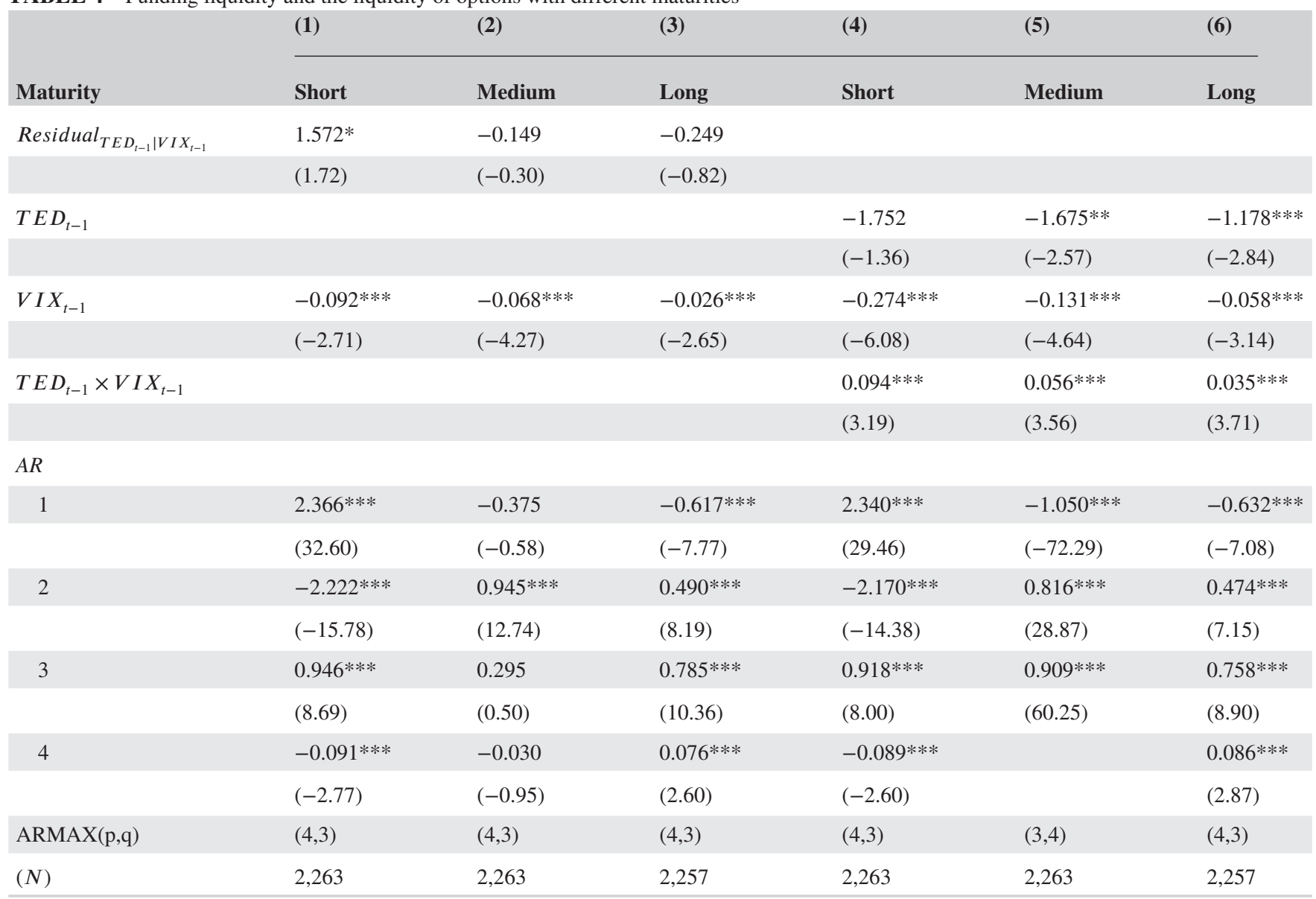

This table shows the results of ARMAX regressions on the liquidity of options with different maturities. An option is considered to be short-term if $A D T E_{i, t}<60$, medium-term if $60 \leq A D T E_{i, t} \leq 180$, and long-term if $180<A D T E_{i, t}$. Columns (1)-(3) include lagged VIX and lagged Residual ${ }_{T E D \mid V I X}$ as exogenous regressors, while Columns (4)-(6) add the interaction term between VIX and the TED spread into the regression. $T$-statistics are shown below the coefficient estimates inside parentheses. Below the exogenous regressors are several autoregressive terms for each ARMAX model. For brevity, the coefficients of moving averaging terms are not displayed. ***, **, and $*$ denote significance at $1 \%, 5 \%$, and $10 \%$ levels, respectively.

options' liquidity is significantly negatively correlated with VIX. The coefficient becomes positive in columns (5) and (10), in which the PBA spread of DITM options is the dependent variable. While no single explanation for this phenomenon may exist, one possibility could be that investors are less likely to trade DITM options, which become more costly during periods of high volatility. This arises from the fact that DITM options are unable to hedge uncertainty but have a high premium compared with ATM or OTM options. As a result, the liquidity of these options decreases with VIX.

Columns (6)-(10) indicate that the conditional effect of funding liquidity seems to exist only for DOTM, OTM, and ATM options. The liquidity of DITM options is only related to the TED spread unconditionally. In other words, the effect of the TED spread on the liquidity of DITM options does not vary with VIX. The liquidity of in-the-money options appears to be very insensitive to changes in funding costs, as it is not related to the TED spread either in an unconditional or a conditional manner.

\subsubsection{Call and put moneyness}

We further examine whether the effect of funding liquidity on options liquidity differs between call and put options with different levels of moneyness. To this end, we split the call and put subsamples into five categories based on the moneyness of each option. Panel A of Table 6 shows the results of ARMAX regressions on the liquidity of call options with different levels of moneyness. In contrast to the main results in Table 3 for call options, the liquidity of ATM, ITM and DITM call options is found to have a significant reaction to shocks to funding liquidity. As shown in columns (3)-(5), the coefficient of Residual TED|VIX $_{\text {is positive }}$ and statistically significant, especially when DITM call options liquidity is the dependent variable.

Columns (6)-(10) investigate the "conditional" effect of funding liquidity on the liquidity of options with various levels of moneyness. While the coefficient of the interaction term is positive in all specifications, it is only significant for OTM, ATM 
TABLE 5 Funding liquidity and the liquidity of options with different levels of moneyness

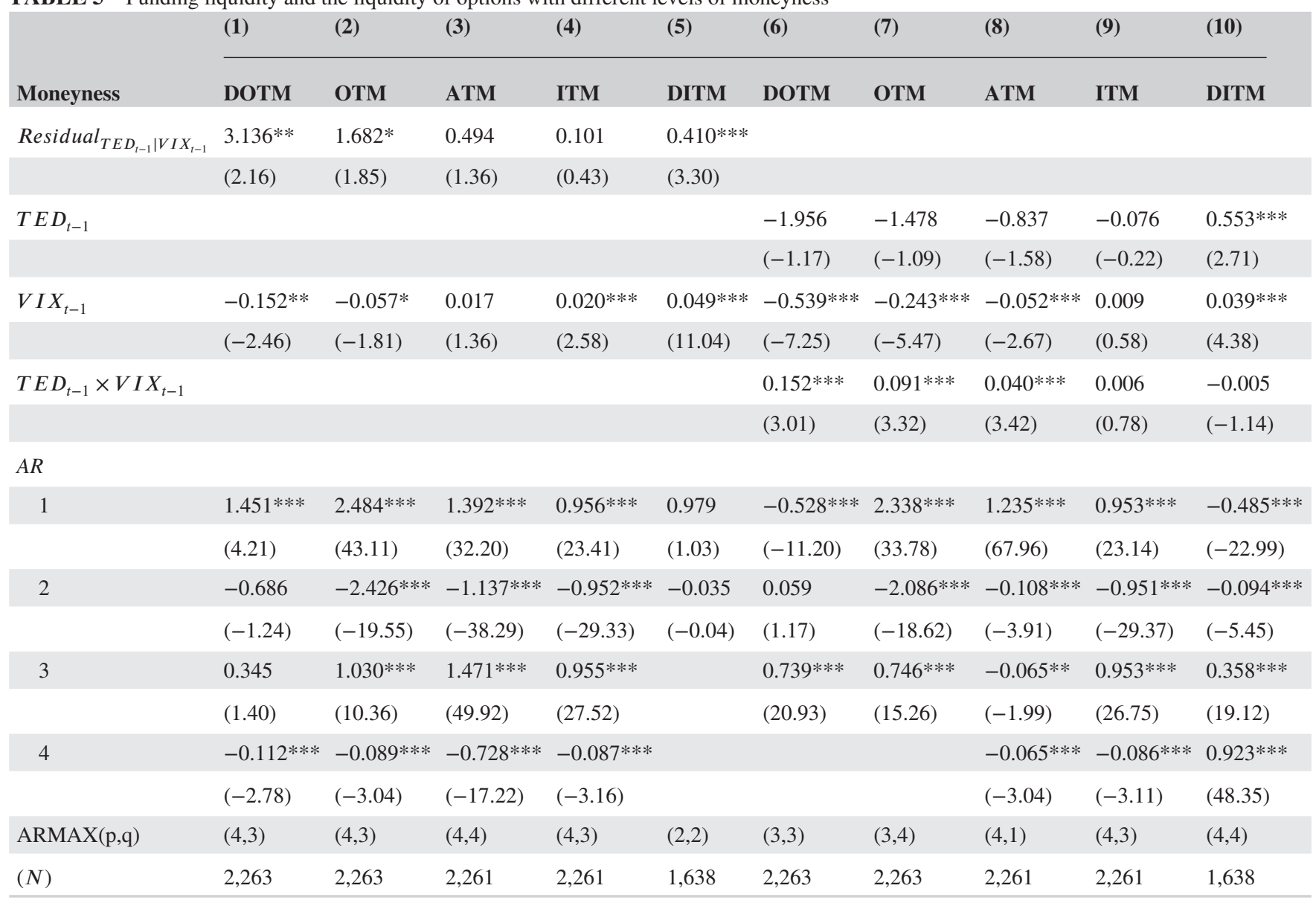

This table shows the results of ARMAX regressions on the liquidity of options with different levels of moneyness. An option is considered to be deep out-of-the-money (DOTM) if the contract is a call and $m_{i, t}>1.06$ or if the contract is a put and $m_{i, t}<0.94$, out-of-the-money (OTM) if the contract is a call and $1.01<m_{i, t} \leq 1.06$ or if the contract is a put and $0.94 \leq m_{i, t}<0.99$, at-the-money (ATM) if $0.99 \leq m_{i, t} \leq 1.01$ for both puts and calls, in-the-money (ITM) if the contract is a call and $0.94 \leq m_{i, t}<0.99$ or if the contract is a put and $1.01<m_{i, t} \leq 1.06$, and deep in-the-money (DITM) if the contract is a call and $m_{i, t}<0.94$ or if the contract is a put and $m_{i, t}>1.06$. Columns (1)-(5) include lagged VIX and lagged Residual ${ }_{T E D \mid V I X}$ as exogenous regressors, while Columns (6)-(10) add the interaction term between VIX and the TED spread into the regression. Below the exogenous regressors are several autoregressive terms for each ARMAX model. For brevity, the coefficients of moving averaging terms are not displayed. $T$-statistics are shown below the coefficient estimates inside parentheses. $* * *, * *$, and $*$ denote significance at $1 \%, 5 \%$ and $10 \%$ levels, respectively.

and ITM calls. For these three types of call options, funding costs start to have a positive impact on options' liquidity when VIX is above $26-30 \%$.

We then turn to put options in Panel B. Similar to call options, the estimated coefficients of Residual ${ }_{T E D \mid V I X}$ are significantly positive for all categories except the DOTM and OTM options. Another commonality between call and put options is that the response of options' liquidity to VIX shocks varies substantially based on moneyness. One distinctive finding for put options is the "conditional" effect. Although not all types of put options' liquidity responds to shocks to funding cost in a significant way, the conditional effect prevails. As indicated in columns (6)-(10), the interaction term is always positive and highly significant. The turning point of VIX around which the effect of funding costs on puts liquidity becomes positive lies between $23 \%$ and $30 \%$. Surprisingly, the DITM put options exhibit a totally different way of responding to funding liquidity shocks than other types of options. The impact of the TED spread on the liquidity of DITM puts is significantly positive. As indicated by the significantly positive interaction term, the above positive effect is then reinforced by increasing market uncertainty.

\section{4 | ROB UST NESS}

We conduct two robustness tests in this section. First, we try to rule out an alternative explanation that the observed FL-ML relationship in the options market results from an association between funding liquidity and liquidity in the equity market. Second, we test our hypotheses using weekly data. 
TABLE 6 Funding liquidity and the liquidity of call and put options with different levels of moneyness

\begin{tabular}{|c|c|c|c|c|c|c|c|c|c|c|}
\hline & (1) & (2) & (3) & (4) & (5) & (6) & (7) & (8) & (9) & (10) \\
\hline Moneyness & DOTM & OTM & ATM & ITM & DITM & DOTM & OTM & ATM & ITM & DITM \\
\hline \multirow[t]{2}{*}{ Residual $_{T E D_{t-1} \mid V I X_{t-1}}$} & 3.900 & 1.297 & $0.427 *$ & $0.292 *$ & $0.327 * * *$ & & & & & \\
\hline & $(1.56)$ & (1.59) & $(1.88)$ & (1.76) & $(3.40)$ & & & & & \\
\hline$T E D_{t-1}$ & & & & & & $(0.23)$ & $(-1.53)$ & $(-2.92)$ & $(-1.52)$ & $(0.49)$ \\
\hline \multirow[t]{2}{*}{$V I X_{t-1}$} & $-0.322 * *$ & $-0.133 * * *$ & 0.011 & $0.038 * * *$ & $0.041 * * *$ & $-0.510 * * *$ & $-0.281 * * *$ & $-0.046 * * *$ & 0.011 & $0.027 * * *$ \\
\hline & $(-2.40)$ & $(-3.22)$ & $(0.99)$ & $(4.98)$ & $(10.27)$ & $(-2.99)$ & $(-5.02)$ & $(-3.04)$ & $(0.92)$ & (3.97) \\
\hline$T E D_{t-1} \times V I X_{t-1}$ & & & & & & 0.074 & $0.090 * * *$ & $0.039 * * *$ & $0.018 * * *$ & 0.005 \\
\hline$(N)$ & 2182 & 2207 & 2205 & 2178 & 1286 & 2182 & 2207 & 2205 & 2178 & 1286 \\
\hline \multicolumn{11}{|l|}{ Panel B: Put options } \\
\hline \multirow[t]{2}{*}{ Residual $_{T E D_{t-1} \mid V I X_{t-1}}$} & 1.251 & 0.569 & $0.475 * *$ & $0.459 * *$ & $0.385^{* * *}$ & & & & & \\
\hline & $(1.15)$ & $(1.31)$ & $(2.15)$ & $(2.46)$ & $(3.36)$ & & & & & \\
\hline \multirow[t]{2}{*}{$T E D_{t-1}$} & & & & & & -2.656 & $-1.823 * *$ & $-0.954 * *$ & -0.524 & $0.367 *$ \\
\hline & & & & & & $(-1.42)$ & $(-2.35)$ & $(-2.38)$ & $(-1.56)$ & $(1.70)$ \\
\hline \multirow[t]{2}{*}{$V I X_{t-1}$} & $-0.209 * * *$ & $-0.071 * * *$ & 0.003 & 0.017 & $0.037 * * *$ & $-0.357 * * *$ & $-0.162 * * *$ & $-0.051 * * *$ & -0.022 & 0.014 \\
\hline & $(-3.71)$ & $(-3.05)$ & $(0.23)$ & $(1.62)$ & (4.99) & $(-4.79)$ & $(-4.92)$ & $(-2.87)$ & $(-1.33)$ & $(1.20)$ \\
\hline
\end{tabular}

This table shows the results of ARMAX regressions on the liquidity of call and put options with different levels of moneyness. Panel A focuses on call options and Panel B presents the results for put options. An option is considered to be deep out-of-the-money (DOTM) if the contract is a call and $m_{i, t}>1.06$ or if the contract is a put and $m_{i, t}<0.94$, out-of-the-money (OTM) if the contract is a call and $1.01<m_{i, t} \leq 1.06$ or if the contract is a put and $0.94 \leq m_{i, t}<0.99$, at-the-money (ATM) if $0.99 \leq m_{i, t} \leq 1.01$ for both puts and calls, in-the-money (ITM) if the contract is a call and $0.94 \leq m_{i, t}<0.99$ or if the contract is a put and $1.01<m_{i, t} \leq 1.06$, and deep in-the-money (DITM) if the contract is a call and $m_{i, t}<0.94$ or if the contract is a put and $m_{i, t}>1.06$. Columns (1)-(5) in both panels include lagged VIX and lagged Residual ${ }_{T E D \mid V I X}$ as exogenous regressors, while Columns (6)-(10) add the interaction term between VIX and the TED spread into the regression. Below the exogenous regressors are several autoregressive terms for each ARMAX model. For brevity, the coefficients of autoregressive and moving averaging terms are not displayed. $T$-statistics are shown below the coefficient estimates inside parentheses. ***, **, and * denote significance at the $1 \%, 5 \%$, and $10 \%$ levels, respectively.

\section{1 | Controlling for stock market liquidity}

There are a number of reasons to expect a connection between the equity market and index options market liquidity. For instance, liquidity exhibits comovement across asset classes; thus, options market liquidity may be driven by the common influences of systemic shocks on the liquidity of the equity market. In particular, the liquidity of the underlying assets is closely related to that of their corresponding derivatives. We use three variables to proxy for aggregate stock market liquidity, namely the bid-ask spread, the trading volume, and the dollar volume. Equity market data are collected from CRSP. The method used to calculate stock liquidity measures can be found in the Appendix.

Table 7 shows the results of the ARMAX regressions linking options market liquidity, stock market liquidity, and funding liquidity. First, we use equal- and value-weighted stock market bid-ask spread as equity liquidity measures. The first two columns report the results. Consistent with the results of Cao and Wei (2010), the liquidity of the options market is closely linked to that of the equity market. ${ }^{10}$ The coefficient of the stock market bid--ask spread is positive, though only the value-weighted

\footnotetext{
${ }^{10}$ Note that the positive coefficient seems to be inconsistent with the pattern of options and stocks bid-ask spreads shown in Figures 1 and 4 . However, this positive correlation is net of the effects of other factors that affect both the stock market liquidity and options liquidity, such as VIX and the TED spread.
} 
TABLE 7 Funding liquidity and options liquidity: controlling for stock market liquidity

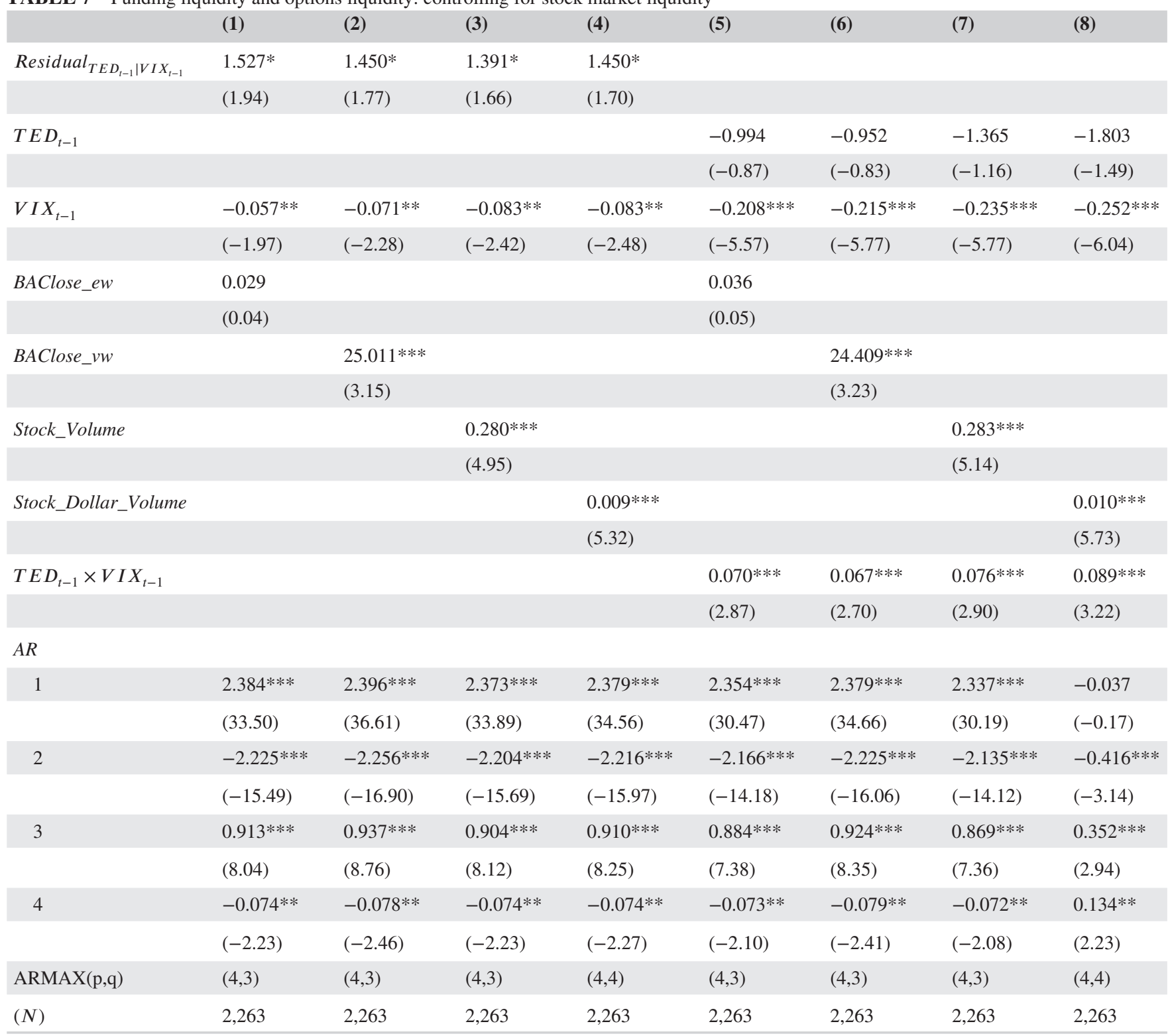

This table shows the results of ARMAX regressions linking liquidity in the options market to stock market liquidity. BAClose_ew and BAClose_vw are equal-and valueweighted closing stock bid-ask spreads for the whole market, respectively. The other two regressors are Stock_Volume and Stock_Dollar_Volume, which denote the trading volume and dollar volume of the whole stock market, both scaled down by 1 billion dollars. Columns (1)-(4) include lagged VIX, lagged Residual stock market liquidity measures as exogenous regressors, while Columns (5)-(8) add the interaction term between lagged VIX and lagged TED spread into the regression. $T$-statistics are shown below the coefficient estimates inside parentheses. Below the exogenous regressors are several autoregressive terms for each ARMAX model. For brevity, the coefficients of moving averaging terms are not displayed. ***, **, and $*$ denote significance at the $1 \%, 5 \%$, and $10 \%$ levels, respectively.

measure is statistically significant. Importantly, the coefficients on Residual $_{T E D \mid V I X}$ remain significant and their signs are positive. This implies that the effect of funding liquidity on options liquidity remains after controlling for equity market liquidity. In columns (3) and (4), we use trading volume and dollar volume as proxies for stock liquidity and obtain similar results. After controlling for VIX and equity market liquidity, there is still a positive relationship between options market liquidity and funding liquidity. We then add the interaction term between the TED spread and VIX. As shown in columns (5)-(8), the coefficient of the TED spread becomes insignificant and negative, but the coefficient on the interaction term is significantly positive. These findings are similar to those shown in Table 3.

\subsection{Weekly data sample}

In Table 8, we re-examine our main findings using weekly data. Compared with the daily time series, weekly data are characterized by much lower volatility and therefore allow us to make more reliable inferences. We calculate the proportional bid-ask 


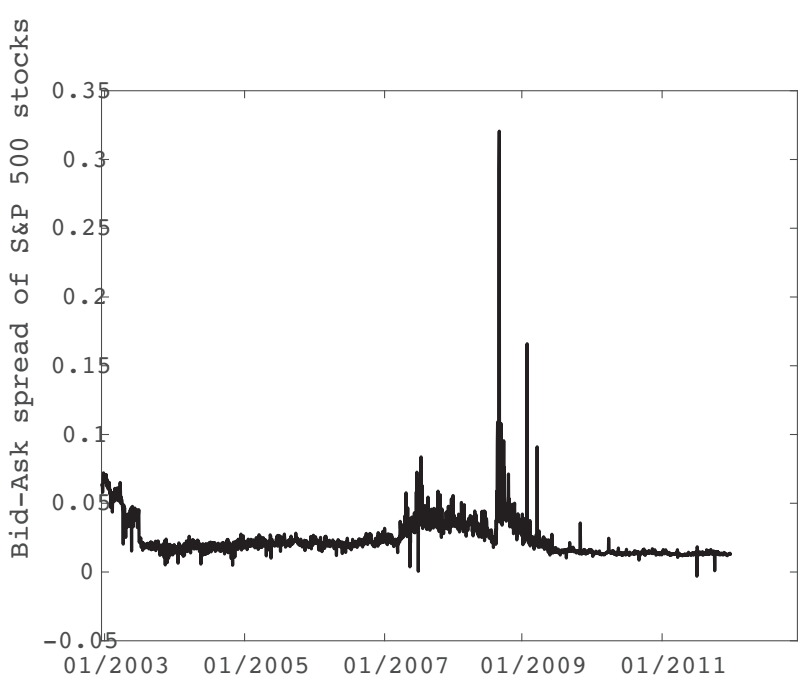

FIGURE 4 The evolution of stock market liquidity. This figure illustrates the evolution of stock market liquidity from January 2003 to January 2012. The value-weighted bid-ask spread is used as a proxy for stock market liquidity

TABLE 8 Funding liquidity and options market liquidity: weekly data

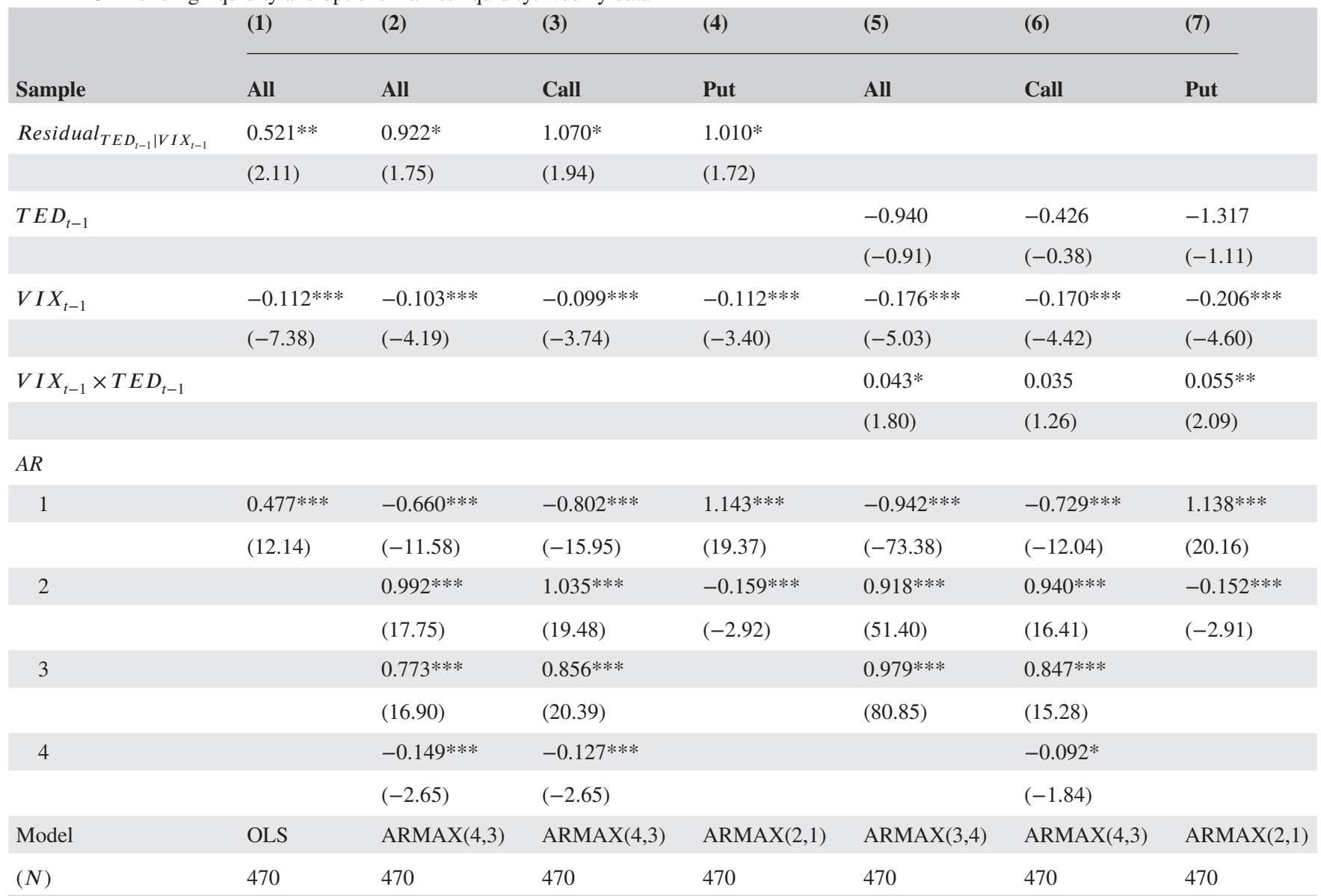

This table shows the results of OLS and ARMAX regressions linking liquidity in the options market to funding costs and VIX using weekly data. In addition to estimating the liquidity of all options in aggregate, the table also presents results for call and put options separately. Columns (1)-(4) include lagged VIX and lagged Residual ${ }_{T E D \mid V I X}$ as exogenous regressors, while Columns (5)-(7) add the interaction term between TED spread and VIX into the regression. $T$-statistics are shown below the coefficient estimates inside parentheses. Below the exogenous regressors are several autoregressive terms for each ARMAX model. For brevity, the coefficients of moving averaging terms are not displayed. ***, **, and $*$ denote significance at the $1 \%, 5 \%$ and $10 \%$ levels, respectively. 
spread on a weekly basis and use weekly VIX and Residual ${ }_{T E D \mid V I X}$ as exogenous regressors. In general, the results are similar to those for the daily sample. Consistent with the results in Table 3 , an increase in market uncertainty in week $t-1$ is followed by a decrease in the PBA spread in week $t$, irrespective of the sample used. It is also worth noting that Residual $\operatorname{TED|VIX}_{\text {is }}$ always positively related to the PBA spread. Probably due to the lower volatility of weekly data, the coefficient magnitude of Residual $_{T E D \mid V I X}$ has declined compared with the main results. In columns (5)-(7), we investigate the "conditional" effect using weekly data. Again, we observe that the effect of the TED spread on options liquidity becomes much stronger as VIX is high while the effect is insignificant when the level of uncertainty is low. This "conditional" effect is especially sizable for put options. All in all, results using the weekly sample confirm the main findings.

\section{5 | CONCLUSION}

Funding liquidity and its impact on market liquidity have recently gained prominence in the academic literature. Most studies investigate the relationship between funding liquidity and market liquidity from a theoretical point of view. For instance, Brunnermeier and Pedersen (2009) explain that a large market-wide decline in prices reduces the ease with which market makers can obtain funding, which leads to higher comovement in market liquidity during recessions. Other recent studies examine the FL-ML relationship in stocks, corporate bonds, and foreign exchange markets. However, none of these antecedents focus on the relationship between funding liquidity and options market liquidity. This paper presents one of the first empirical studies of liquidity in the S\&P 500 index options market, with a particular focus on the FL-ML relationship.

Using data on the S\&P 500 index options traded on the CBOE market from January 17, 2003 to January 31, 2012, we establish convincing evidence of a positive relationship between funding liquidity and options market liquidity, especially during periods of high market uncertainty. More specifically, we find a positive and statistically significant relationship between the PBA spread and the TED spread. In addition, this effect is much stronger for various types of options, such as puts, short-term options, deep in-the-money and deep out-of-the-money options, etc. These empirical findings lend support to the hypothesis that market liquidity declines when liquidity providers face high funding costs. Interestingly, most of our findings are likely to be "conditional" on high levels of VIX, which implies that the FL-ML relationship becomes more significant during periods of high market uncertainty.

This paper serves as a first step toward understanding the relationship between funding liquidity and index options market liquidity during periods of high market uncertainty. It opens up several avenues for future research. One natural extension would be an in-depth examination of the relationship between funding liquidity and individual options market liquidity. Another area of future research would be to investigate the effect of funding constraints on the pricing of index options.

\section{ACKNOWLEDGMENTS}

We thank Yakov Amihud, Jonas Andersson, Jens Dick-Nielsen, Massimo Guidolin, Jianfeng Hu, Christian Julliard, Meiman Lin, Breno Neri, Dimitri Vayanos, Robert Webb (the editor) and participants at the 5th Annual Financial Market Liquidity Conference, the Midwest Finance Association 2015 Annual Meeting, and the 6th International Conference on Futures and Other Derivatives for helpful comments.

\section{OR CID}

Cheng Zhang (D) http://orcid.org/0000-0001-9238-0669

\section{REFERENCES}

Bakshi, G., Cao, C., \& Chen, Z. (1997). Empirical performance of alternative option pricing models. The Journal of Finance, 52, 2003-2049.

Bongaerts, D., de Jong, F., \& Driessen, J. (2011). Derivative pricing with liquidity risk: Theory and evidence from the credit default swap market. The Journal of Finance, 66, 203-240. 
Boyson, N. M., Stahel, C. W., \& Stulz, R. M. (2010). Hedge fund contagion and liquidity shocks. The Journal of Finance, 65, 1789-1816.

Brunnermeier, M. K., Nagel, S., \& Pedersen, L. H. (2008). Carry trades and currency crashes (Techical Report). National Bureau of Economic Research.

Brunnermeier, M. K., \& Pedersen, L. H. (2009). Market liquidity and funding liquidity. Review of Financial Studies, 22, 2201-2238.

Cao, C., Chen, Z., \& Griffin, J. M. (2003). Informational content of option volume prior to takeovers. The Journal of Business, 78, 1073-1109.

Cao, M., \& Wei, J. (2010). Option market liquidity: Commonality and other characteristics. Journal of Financial Markets, 13, $20-48$.

Cetin, U., Jarrow, R., Protter, P., \& Warachka, M. (2006). Pricing options in an extended black scholes economy with illiquidity: Theory and empirical evidence. Review of Financial Studies, 19, 493-529.

Chordia, T., Roll, R., \& Subrahmanyam, A. (2000). Commonality in liquidity. Journal of Financial Economics, 56, 3-28.

Chordia, T., Sarkar, A., \& Subrahmanyam, A. (2005). An empirical analysis of stock and bond market liquidity. Review of Financial Studies, 18, 85-129.

Coffey, N., Hrung, W. B., \& Sarkar, A. (2009). Capital constraints, counterparty risk, and deviations from covered interest rate parity (Technical Report). Staff Report, Federal Reserve Bank of New York.

Deuskar, P., Gupta, A., \& Subrahmanyam, M. G. (2011). Liquidity effect in otc options markets: Premium or discount? Journal of Financial Markets, $14,127-160$.

Dick-Nielsen, J., Gyntelberg, J., \& Lund, J. (2013). From funding liquidity to market liquidity: Evidence from danish bond markets (Working Paper). Copenhagen Business School.

Duffie, D. (2010). Presidential address: Asset price dynamics with slow-moving capital. The Journal of Finance, 65, $1237-1267$.

Duffie, D. (2012). Market making under the proposed volcker rule (Working Paper). Rock Center for Corporate Governance at Stanford University.

Easley, D., O’hara, M., \& Srinivas, P. S. (1998). Option volume and stock prices: Evidence on where informed traders trade. The Journal of Finance, 53, 431-465.

Garleanu, N., \& Pedersen, L. H. (2007). Liquidity and risk management. American Economic Review, 97, $193-197$.

George, T. J., \& Longstaff, F. A. (1993). Bid-ask spreads and trading activity in the s\&p 100 index options market. Journal of Financial and Quantitative Analysis, 28, 381-397.

Goncalves, S., \& Guidolin, M. (2006). Predictable dynamics in the s\&p 500 index options implied volatility surface. The Journal of Business, 79, $1591-1636$.

Greene, W. H. (2011). Econometric analysis. Upper Saddle River, NJ: Prentice Hall.

Gromb, D., \& Vayanos, D. (2002). Equilibrium and welfare in markets with financially constrained arbitrageurs. Journal of Financial Economics, 66, 361-407.

Hameed, A., Kang, W., \& Viswanathan, S. (2010). Stock market declines and liquidity. The Journal of Finance, 65, $257-293$.

Hu, B., Jain, C., \& Jain, P. (2013). Dynamics of market liquidity and funding liquidity during the crisis, its resolution, and the volcker rule (Working Paper). Akansas State University.

Jameson, M., \& Wilhelm, W. (1992). Market making in the options markets and the costs of discrete hedge rebalancing. The Journal of Finance, 47, 765-779.

Jayaraman, N., Frye, M. B., \& Sabherwal, S. (2001). Informed trading around merger announcements: an empirical test using transaction volume and open interest in options market. Financial Review, 36, 45-74.

Mancini, L., Ranaldo, A., \& Wrampelmeyer, J. (2013). Liquidity in the foreign exchange market: Measurement, commonality, and risk premiums. The Journal of Finance, 68, 1805-1841.

Newey, W. K., \& West, K. D. (1987). A simple, positive semi-definite, heteroskedasticity and autocorrelation consistent covariance matrix. Econometrica, 55, 703-708.

Vijh, A. M. (1990). Liquidity of the cboe equity options. The Journal of Finance, 45, 1157-1179.

Wei, J., \& Zheng, J. (2010). Trading activity and bid-ask spreads of individual equity options. Journal of Banking and Finance, 34, 2897-2916.

Wu, W.-S., Liu, Y.-J., Lee, Y.-T., \& Fok, R. C. (2014). Hedging costs, liquidity, and inventory management: the evidence from option market makers. Journal of Financial Markets, 18, 25-48.

How to cite this article: Liu C, Zhang C, Zhou Z. From funding liquidity to market liquidity: Evidence from the index options market. J Futures Markets. 2018;38:1189-1205. https://doi.org/10.1002/fut.21920 


\section{APPENDIX}

\section{Variable definitions}

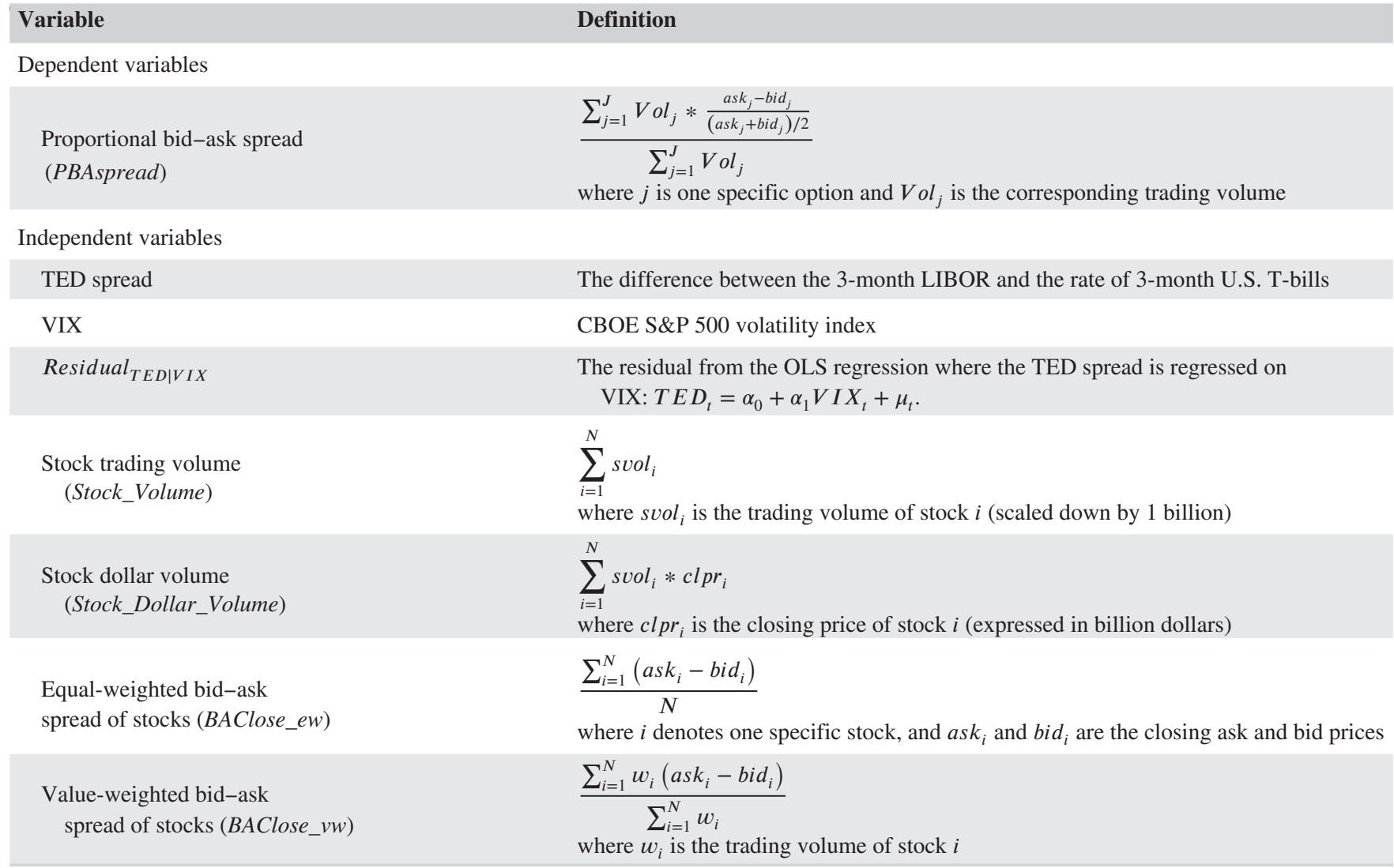

